Sports Training

\title{
Physiological and technical demands of the small-sided and generic games in female futsal players
}

\author{
José Leandro T. Da $\operatorname{Costa}^{1}$ (D), Higor Spineli ${ }^{1,2}$ (D), Pedro Balikian Júnior ${ }^{1}$ (D), \\ Eduardo S. Prado ${ }^{1}$ (D) Gustavo G. De Araujo ${ }^{1,2}$ \\ ${ }^{1}$ Universidade Federal de Alagoas, Instituto de Educação Física e Esporte, Laboratório de \\ Ciências Aplicadas ao Esporte, Maceió, AL, Brazil; ${ }^{2}$ Universidade Federal de Alagoas, Instituto \\ de Ciências Biológicas e Saúde, Maceió, AL, Brazil.
}

Associate Editor: Ricardo Barbieri. Estácio UniSEB, Ribeirão Preto, SP, Brasil.

\begin{abstract}
Aim: This study aimed to compare the heart rate (HR) values and technical actions frequencies during small-sided (SSG) and generic (GG) games in women futsal players. Methods: Six futsal players (age: $20.5 \pm$ 7.4 years, height: $163.3 \pm 16 \mathrm{~cm}$, body mass: $57.9 \pm 22 \mathrm{~kg}$, maximum rate of oxygen consumption $\left(\mathrm{VO}_{2} \mathrm{max}\right): 42.0 \pm$ $9 \mathrm{~mL} . \mathrm{kg} \cdot \mathrm{min}^{-1}$ ) performed two experimental conditions in two days separated for at least $72 \mathrm{~h}$ of interval: (1) one set of $10 \mathrm{~min}$ of SSG, $3 \times 3$ players; and (2) one set of $10 \mathrm{~min}$ of GG, 4 (1 joker) x 4 (1 joker) players. During each experimental session, the subject's HR values were monitored every $1 \mathrm{~min}$ of play. Pass, shot, dribbling, driving, and disarmament were recorded during the games. Results: There was no difference between SSG and GG for HR average $(p=0.50)$. The HR values that were recorded at the first minute of GG were higher than SSG ( $p=0.02)$. The HRmax in SSG and GG were equivalent to $91.9 \%$ and $90.8 \%$ of HRmax of the incremental test, respectively. Total technical actions were higher in SSG $(+18.4 \%, p=0.001)$ than GG. Pass was higher in the SSG $(+16 \% ; p=0.01)$ in comparison to GG.

Conclusion: Both models were higher than HRmax equivalent to AT velocity. The technical actions of the SSG were higher than GG, suggesting that the SSG model is a suitable technical and physiological stimulus for the development of female futsal players.
\end{abstract}

Keywords: soccer, women, sports, athletic performance, exercise.

\section{Introduction}

Futsal game has been characterized by periods of highintensity, short-duration, interspersed periods of low-intensity, and intermittent actions ${ }^{1,2}$. Different training methods have been proposed to develop specific physical performance ${ }^{3-5}$. Small-sided games (SSG) have been widely studied and become a popular method to improve at the same time the physical fitness (i.e., maximal oxygen uptake, anaerobic threshold, and specific endurance performance) and technical variables ${ }^{5,6}$. Some studies reported that SSG has been more effective than generic games (GG) to improve specific aerobic fitness in soccer $^{7}$, and technical variables in soccer ${ }^{5}$, futsal ${ }^{2}$, and other team sports $^{4}$. In SSG, the field dimension and the number of players can be manipulated ${ }^{8}$, increasing the ball contact per individual, offensive and defensive actions ${ }^{9,10}$, and the ecological validity ${ }^{3-5}$. Although the small-sided game's physiological responses are well established in male players, no study to date was conducted in female futsal players hindering the: (1) data transfer for application, (2) characterization of the physical and technical profile in the different methods (i.e., size field reduction, number of ath- letes, recovery, duration of the session, and others), and (3) reference values.

The heart rate (HR) has been a sensible variable to control the game and training session intensity/load in team sports ${ }^{7,11-13}$. A previous study reported that male players spend $80 \%$ of game time at intensities higher than $85 \%$ of heart rate maximal (HRmax) $)^{14,15}$. Although the studies indicate that manipulation in the number of players and field dimension in the soccer game ${ }^{11}$ can alter the HR, more studies are necessary to characterize and standardize the physiological responses of different training methods in female futsal players. Three studies reported values between $85 \%$ and $90 \%$ of maximal heart rate (HRmax) during simulated and official matches of female futsal ${ }^{16-18}$, while in soccer players, was found HRmax up to $95 \%{ }^{5}$. Naser et al. ${ }^{2}$ reported values above $80 \%$ of HRmax in futsal matches and these values are equal or higher to soccer matches and other sports. One recent study ${ }^{15}$ reported male players that lower limb blood flow restriction during SSG increases the HR, internal training load, and aerobic and anaerobic markers of performance ${ }^{15}$. However, it is unclear whether manipulations in the number of players and the playing field's 
size can boost the physiological demand and technical actions in futsal players.

Thus, the present study aimed to compare the HR values and technical actions frequencies during SSG and GG in women futsal players. Secondarily, was analyzed the difference in HR of the SSG and GG in relation to the HR of the anaerobic threshold (AT). It was hypothesized that the HR values and the number of technical actions during SSG are higher than GG.

\section{Material and methods}

\section{Participants}

Six female futsal players (age $=20.5 \pm 7.4$ years, mass $=57.95 \pm 22 \mathrm{~kg}$, height $=63.3 \pm 16 \mathrm{~cm}, \mathrm{VO}_{2} \max =$ $42.0 \pm 9 \mathrm{~mL} . \mathrm{kg} . \mathrm{min}^{-1}$ ) with at least 2 years experience in futsal (national and regional competitions), training frequency of 3 times per week, $2 \mathrm{~h}$ of training per session were recruited. Two goalkeepers performed both protocols and 2 jokers specifically from GG. These participants were members of the same futsal team but did not have the data collected.

All the players were instructed not to drink alcohol or ergogenic substances, not practice vigorous physical activity during the previous $24 \mathrm{~h}$ and maintain their dietary habits, including hydration.

The experimental procedures were conducted under the Declaration of Helsinki (2008) and approved by the local Ethics Committee inserir nome da Universidade e ano aprovação no processo (Protocol number: 1.392.005).

\section{Experimental design}

The participants visited the laboratory 1 time and the field 2 times, at least $72 \mathrm{~h}$ apart (Figure 1): 1) maximum incremental test to determine anaerobic threshold (AT), maximum oxygen uptake $\left(\mathrm{VO}_{2} \max \right)$, and $\left.\mathrm{HRmax} ; 2\right) \mathrm{GG}$ field tests (with $80 \mathrm{~m}^{2}$ per player); 3) SSG field tests (with $25 \mathrm{~m}^{2}$ per player). For further analysis, the game was recorded, and HR was collected minute by minute until $10 \mathrm{~min}$.

Both games were conducted according to official FIFA $^{\circledR}$ rules and there was no guidance, leaving the athlete's decision-making free of any external manipulation. Besides, there were 5 balls (Penalty Max ${ }^{\circledR}$ ) near the play area to facilitate the reset.

\section{Maximal incremental test}

The incremental test consisted of progressive running in the treadmill (Treadmill ATL, Inbrasport ${ }^{\circledR}$ ). The protocol involved running on a flat treadmill with a 3-min warm-up period at $5 \mathrm{~km} \cdot \mathrm{h}^{-1}$ and increments of $1 \mathrm{~km} \cdot \mathrm{h}^{-1}$ per minute until exhaustion, with data being collected every $10 \mathrm{~s}^{19}$. Oxygen consumption $\left(\mathrm{VO}_{2}\right)$, carbon dioxide $\left(\mathrm{VCO}_{2}\right)$, and ventilation (VE) were obtained breath-bybreath from an automatic gas exchange analyzer (Quark Cosmed-Roma Italy $($ ). Three of the following criteria were considered maximal: respiratory exchange ratio (RER) $\geq 1.15$, HR $\geq 90 \%$ predicted by age ( 220 - age), and RPE $\geq 18^{20,21}$. Maximum aerobic power was considered as the highest power achieved during the test and the AT assumed in the exact moment of respiratory compensation point identified by three independent evaluators, separately, using the second break in the ventilation curve, an increase in VE-to- $\mathrm{VCO}_{2}$ ratio, and the first drop point
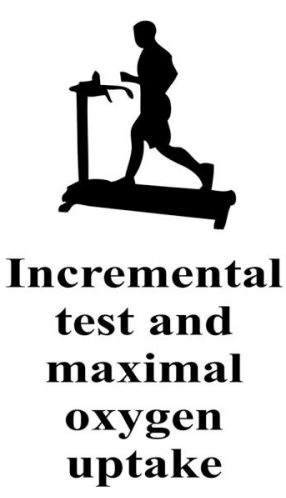

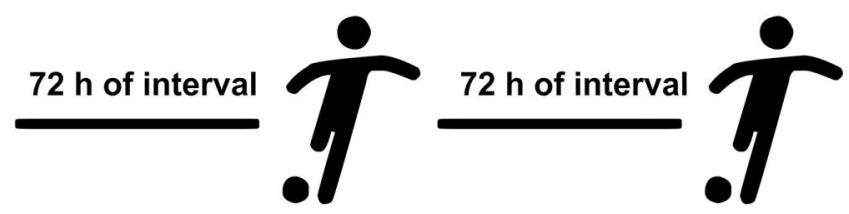

Generic game (10 $\mathrm{min}$ )

$80 \mathrm{~m}^{2}$ per player

4 (1 joker) $x 4$ (1 joker) players +2 goalkeepers

Number of players evaluated -6
Small sided game (10 $\mathrm{min})$

$25 \mathrm{~m}^{2}$ per player

$3 \times 3$ players +2 goalkeepers

No joker

Number of players evaluated -6

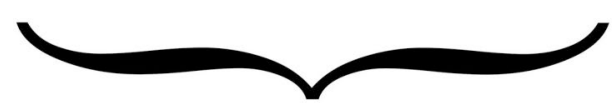

Dependent sample

Figure 1 - Experimental protocol. 
of the $\mathrm{CO}_{2}$ fraction ${ }^{22}$. HR was recorded using an Oregon SE102L ${ }^{\circledR}$ heart rate monitor during the test.

\section{Field tests: Generic Game (GG) and Small-sided Game (SSG)}

All field tests were performed in a multi-sport arena indoor with official dimensions $40 \mathrm{~m} \times 20 \mathrm{~m}$, during 10 min continuous and separated by $72 \mathrm{~h}$ of recovery. The warm-up consisted of $5 \mathrm{~min}$ of standardized movements, callisthenic, running at low intensity, pass, and ball conservation. GG simulated the official game: exact official dimension, 4 ( 1 joker) x 4 ( 1 joker) players, 2 goalkeepers, and a relative area of $80 \mathrm{~m}^{2}$ per player. During SSG, relative square area per player was reduced by $69 \%\left(25 \mathrm{~m}^{2}\right.$ per player), absolute dimension compacted $(20 \mathrm{~m} \times 10 \mathrm{~m})$ and $3 \times 3$ players plus 2 goalkeepers distributed in the field (Figure 1). Players received verbal encouragement from the evaluators for $10 \mathrm{~min}$.

\section{Heart rate}

All players used a heart rate monitor (Oregon SE102L $($ ) and were instructed to indicate the values every minute without interrupting the game. A researcher timed the partial and total time, and two others registered the HR values reported by the players.

\section{Technical actions}

A video camera LG Dual ${ }^{\circledR}$ positioned at the top of the stands ( $5 \mathrm{~m}$ high), was controlled by an evaluator, and recorded all the game situations. The recording was transferred to a computer for technical action quantifications. Technical actions were categorized according to $\mathrm{Mutti}^{23}$ : pass, driving, dribbling, shots on target, disarmament.

- Pass: the action of transferring the ball as a means of communication between the players of the same team.

- Driving: the action of carrying the ball from one area to another on the court.

- Dribbling: individual action with a ball to overtake an opponent keeping it under his control.

- Shot: the player needs greater control of the force and direction, like the pass.

- Disarmament: the action of intercepting the pass or stealing the ball.

\section{Statistical analysis}

Mean, standard deviation, maximum and minimum values were descriptively presented for technical analysis. The Shapiro Wilk test was used to verify the normality of the residues. HR analysis and technical actions were analyzed by paired Student t-test or Wilcoxon (i.e., technical action "disarmament"). Cohen's effect size (d) was calculated for paired posthoc comparisons and interpreted using Cohen's scale as follows ${ }^{24}$ : small (0.2), moderate (0.5), and large (0.8). Statistical analyzes were performed using a statistical package (Statistica ${ }^{\circledR}$ version 10.0, StatSoft).
The level of significance adopted was $\mathrm{p}<0.05$ and $\mathrm{CI}$ $95 \%$.

\section{Results}

HR average between GG and SSG are shown in the Figure 2; no difference was found between both experimental protocols $(\mathrm{p}=0.50 ; d=0.38 ; \mathrm{CI}=-9.90$ and 5.50). The HR average at the velocity equivalent to the anaerobic threshold was lower than GG $(\mathrm{p}=0.01$; $d=1.76, \mathrm{CI}=-16.23$ and -3.17$)$ and SSG $(\mathrm{p}=0.031$; $d=0.99 ; \mathrm{CI}=-14.02$ and -0.98 ).

There was no significant difference between the conditions for the HRmax ( $>0.05$ ). The HRmax during GG $(179.5 \pm 2.52 \mathrm{bpm})$ and SSG $(177.3 \pm 7.8 \mathrm{bpm})$ were equivalent to $91.9 \%$ and $90.8 \%$ of incremental test (195.2 $\pm 8.2 \mathrm{bpm}$ ), respectively. There was difference intra-group for HR between GG and SSG at the first minute $(p=0.02$; $\mathrm{d}=1.28 ; \mathrm{CI}=-18.17$ and -2.16 , Figure 3 ). However, there were no differences intra-group for HR between GG and SSG throughout time (Figure 3). All players in both games achieved an HR greater than $85 \%$ of HRmax.

The average of all technical actions in the SSG was higher (increase of $18.4 \%)$ than GG $(p=0.001)$ (Figure 4). In addition, the pass was higher in SSG compared to GG $(+16 \% ; \mathrm{p}=0.02 ; d=0.3 ; \mathrm{CI}=-4.87-0.79)($ Table 1$)$.

\section{Discussion}

In the present study, we demonstrated that total technical actions and pass were higher in SSG than GG, but the HR average had no difference between the games, refuting the hypothesis partially.

HRmax during GG $(179.5 \pm 2.5 \mathrm{bpm})$ and $\mathrm{SSG}$ $(177.3 \pm 7.8 \mathrm{bpm})$ was equivalent to $91.9 \%$ and $90.8 \%$ of HRmax in the incremental test $(195.2 \pm 8.2 \mathrm{bpm})$. Specifically, about GG in women, Martin-Silva ${ }^{17}$ investigated two official matches in female futsal players $\left(\mathrm{VO}_{2} \mathrm{max}=\right.$

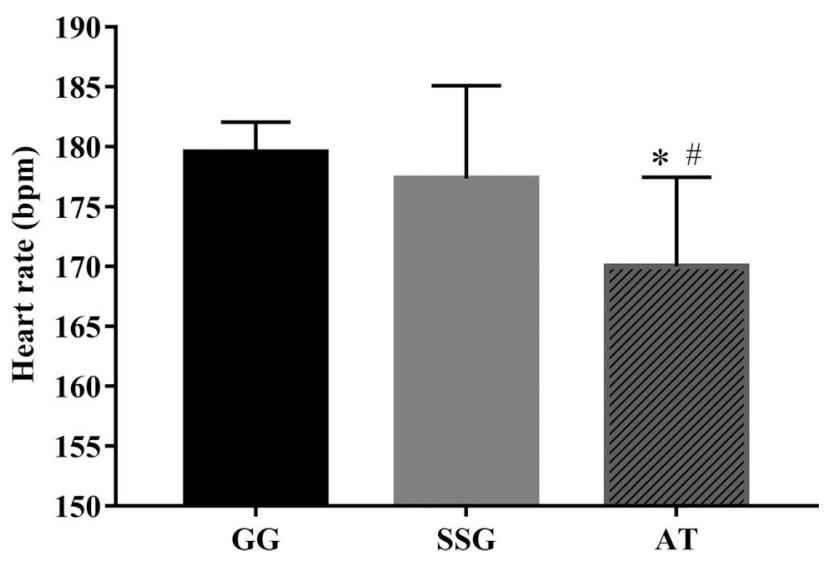

Figure 2 - Comparison of heart rate in GG, SSG, and AT. Data expressed as mean \pm standard deviation. * - significant difference with GG; \# - significant difference with SSG. 


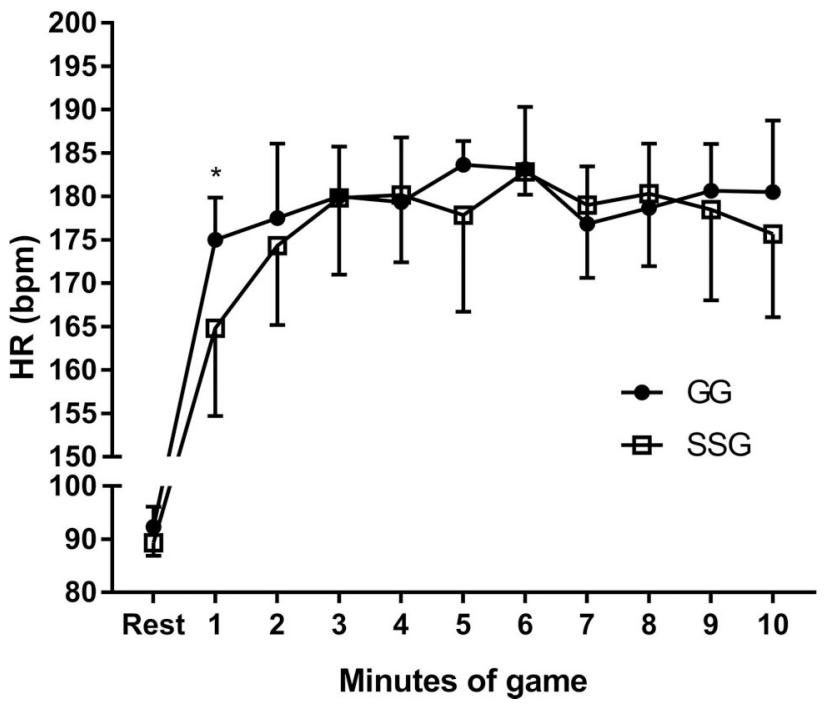

Figure 3 - HR comparison between GG and SSG at rest and every minute. Data expressed as mean \pm standard deviation. * - significant difference with GG.

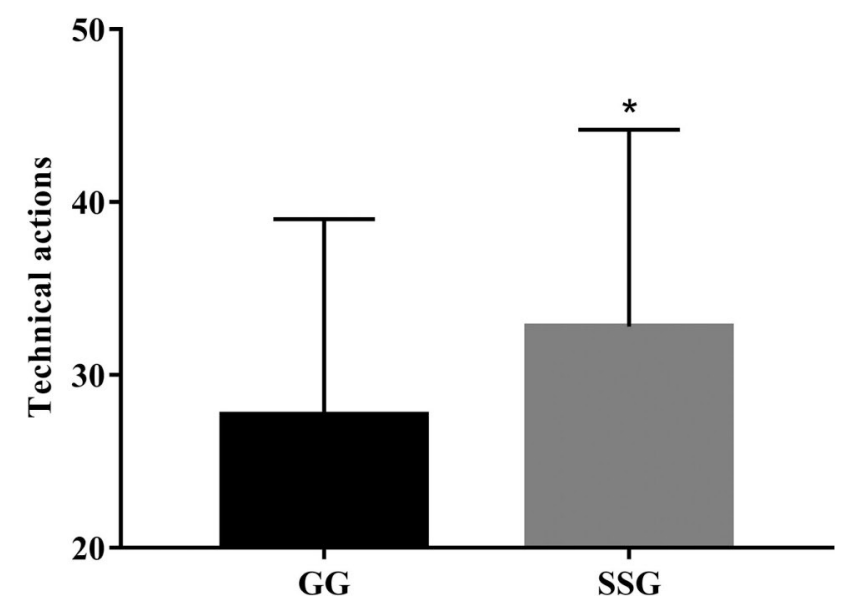

Figure 4 - Comparison of the number of technical actions in the two game situations. Data presented in mean \pm standard deviation for all technical actions grouped. * - significant difference for GG.

$40.0 \pm 3.8 \mathrm{~mL} \cdot \mathrm{kg} \cdot \mathrm{min}^{-1}$ ) and found values of $178 \pm 9$ bpm in a first game and $170 \pm 30 \mathrm{bpm}$ in the second game (equivalent to $89 \%$ and $86 \%$ of HRmax, respectively). Carminatti et al. ${ }^{16}$ pointed out that the average in five official matches was $178 \pm 9 \mathrm{bpm}(91 \%$ of HRmax) with female professional futsal players. Thus, the \% HRmax can be sensitive regardless of physical fitness level. Variations in the number of players in official dimension courts ( $3 \times 3,4 \times 4,5 \times 5$, and $6 \times 6$ ) maintained the HR above $80 \%$ of the HR max, but $3 \times 3$ and $4 \times 4$ models showed higher lactate concentration compared to $6 \times 6$ model, showing that the SSG may be used as a tool to establish specific training zones $^{6}$. Besides, the environment of official matches (i.e., stress, tension, public, and others) does not appear to change HR compared to GG. Concerning male players, the HR values close to $90 \%$ of HRmax were similar to female $\mathrm{GG}^{14}$.

About the SSG, Duarte et al. ${ }^{13}$ evaluated male futsal players and reported values equivalent to $82.2 \%$ of HRmax during 10 -min $(20 \mathrm{~m} \times 20 \mathrm{~m})$ with $4 \times 4$ players, $86.6 \%$ of HRmax during 4-min $(20 \mathrm{~m} \times 20 \mathrm{~m})$ with $3 \times 3$ players, and $87.9 \%$ of HRmax during 4-min ( $20 \mathrm{~m} \times 20 \mathrm{~m})$ with $2 \times 2$ players. A decrease in the number of players at $20 \times 20 \mathrm{~m}$ area increased the intensity and HR. However, these data show a disproportionate time duration and area of 50,66 , and $100 \mathrm{~m}^{2}$ per player in $4 \times 4,3 \times 3$, and $2 \times 2$ situations, respectively. In our study, the area of the GG (40x $20 \mathrm{~m}$ ) was equivalent to $100 \mathrm{~m}^{2}$ per player (without the goalkeepers) and SSG $(20 \mathrm{~m} \times 10 \mathrm{~m})$ equivalent to $33 \mathrm{~m}^{2}$ per player (without the goalkeepers), but the time was the same. In this context, reducing the area per player with the same time duration does not influence the HR average. Perhaps, the same and extended time for both games (10 min continuous) may have reduced the intensity of games and, consequently, the HR average.

There may be differences in technical and physiological demands between different players, with different characteristics, position, duration, intensity, or the game itself and training status ${ }^{13,14}$. Moreover, on futsal, only $0.3 \%$ of playing time is spent in low-intensity with less than $65 \%$ of HRmax, $16 \%$ in moderate intensity approximately $65-85 \%$ of HRmax, and $83 \%$ in very vigorous activity, more than $85 \%$ of $\mathrm{HRmax}^{13,14}$. There is a higher endurance demand in futsal players (i.e.,4313 $\mathrm{m}$ distance covered) ${ }^{14}$ than basketball, handball, and some positions in soccer games $^{2}$. Furthermore, futsal can lead to dehydration, an increase in blood viscosity, causing an increase in $\mathrm{HR}^{25}$.

Another study reported the effectiveness of SSG on aerobic capacity and anaerobic power in futsal when compared to GG model ${ }^{26}$. In a longitudinal study (6-week)

Table 1 - Comparison of average number of specific technical actions performed in GG and SSG.

\begin{tabular}{lccccc}
\hline & Pass & Shot & Dribbling & Disarmament & Driving \\
\hline GG & $17.83 \pm 9.15^{*}$ & $4.00 \pm 2.00$ & $1.50 \pm 1.64$ & $3.33 \pm 1.37$ & $3.00 \pm 3.69$ \\
& $(9.0-29.0)$ & $(1.0-3.0)$ & $(0.0-4.0)$ & $(2.0-5.0)$ & $(0.0-8.0)$ \\
SSG & $20.67 \pm 9.14$ & $2.00 \pm 0.63$ & $1.00 \pm 1.10$ & $4.33 \pm 0.52$ & $2.83 \pm 2.40$ \\
& $(11.0-32.0)$ & $(2.0-7.0)$ & $(0.0-3.0)$ & $(4.0-5.0)$ & $(0.0-6.0)$ \\
$\%$ & $-16 \%$ & $+100 \%$ & $+50 \%$ & $-30 \%$ & $+6 \%$ \\
\hline
\end{tabular}


with young male futsal players, the SSG training provided a similar HR stimulus in the players compared to the GG program and both models improved physical fitness parameters compared to baseline. SSG resulted in better technical performance, representing an effective alternative to developing aerobic capacity and anaerobic power in futsal $^{26}$. We found HR values at AT velocity lower than SSG and GG models, corroborating studies on the characterization of effort intensity in female futsal matches. Thus, our data showing that a game with manipulation of size and players number can be a method with high anaerobic demand ${ }^{16,17,27}$.

The technical actions were higher in SSG than GG. These data corroborate with Katis and Kellis ${ }^{28}$, which verified in SSG $3 \times 3$ + goalkeeper a higher number of shots, short pass, disarmament, and dribbling than $6 \times 6+$ goalkeeper in young soccer players. Jones and Drust ${ }^{29}$, also found a more significant number of technical actions with the reduction of players and the field dimension, precisely $4 \times 4+$ goalkeeper vs. to $8 \times 8+$ goalkeeper, increasing the contacts with the ball almost 3 times during the game in elite youth soccer players. Duarte et al. ${ }^{13}$ found improvement in futsal tactical actions with a $3 \times 3$ and $2 \times 2$ compared a $4 \times 4$ male players in an SSG $(20 \mathrm{~m} \times 20 \mathrm{~m})$, increasing the number of contacts with the ball and dribbling. Our data showed that although there was no increase in shot, dribbling, and disarmament actions, the number of passes $(p=0.016)$ increased in SSG. These findings indicate that a smaller number of players lead to a more significant number of technical actions.

Thus, the $3 \times 3+$ goalkeeper method studied, despite having a square area approximately $69 \%$ smaller than the GG, maintained the HR stimulus adequate for the players and contained a more significant number of technical actions. At this point, the SSG proposal is reinforced in the development of the futsal player since one can work with satisfactory internal loads and at the same time reproduces the technical and tactical requirements found like the generic game.

We can report 3 limitations of our study: (1) the sample size, which was reduced by using only one women's futsal team and did not expand the study to other teams; (2) 10-min protocols can be considered unspecific compared to the duration of official matches; (3) HR collection every minute due to the lack of availability of devices that collect HR more frequently.

\section{Conclusion}

The HR average was no different between SSG ( $3 \times 3$ + goalkeepers, $20 \mathrm{~m} \times 10 \mathrm{~m})$ and $\mathrm{GG}(4 \times 4$ + goalkeepers, $40 \mathrm{~m} \times 20 \mathrm{~m}$ ) and presented a \% HRmax equivalent to $91.9 \%$ and $90.8 \%$ of HRmax in the incremental test. Both models were higher than HRmax equivalent to AT velocity. The technical actions of the SSG were higher than
GG, suggesting that the SSG model is a suitable technical and physiological stimulus for the development of female futsal players. Further studies are needed to add information about the effect of SSG on female futsal players.

\section{Disclosure of interest}

The authors certify that there is no conflict of interest with any financial organization regarding the material discussed in the manuscript.

\section{Acknowledgments}

Futsal players of the Federal University of Alagoas. This study was financed in part by the Coordenação de Aperfeiçoamento de Pessoal de Nível Superior - Brazil (CAPES) - Finance Code 001 and Brazil Citizenship Ministry (Academia\&Futebol).

\section{References}

1. Gonçalves HR, Santana WC. Valores De Frequência Cardíaca De Jogadores De Futsal Em Situação De Jogo. Pensar a Prática. 2013;16.

2. Naser N, Ali A, Macadam P. Physical and physiological demands of futsal. J Exerc Sci Fit. 2017;15:76-80.

3. Dellal A, Varliette C, Owen A, Chirico EN. small-sided games versus interval training in amateur soccer players: effects on the aerobic capacity and the ability to perform intermittent exercises with changes of direction. J Strength Cond Res. 2012;26:2712-20.

4. Hammami A, Gabbett T, Slimani M, Bouhlel E. Does smallsided games training improve physical ftness and teamsport-specifc skills? a systematic review and meta-analysis. J Sport Med Phys Fit. 2018;58:1446-55.

5. Impellizzeri FM, Marcora SM, Castagna C, Reilly T, Sassi A, Iaia FM, R et al. Physiological and performance effects of generic versus specific aerobic training in soccer players. Int J Sports Med. 2006;27(6):483-92.

6. Hulka K, Weisser R. The influence of the number of players on workload during small-sided games among elite futsal players. Monten J Sport Sci Med. 2017;6:45-8.

7. Impellizzeri FM, Rampinini E, Marcora SM. Physiological assessment of aerobic training in soccer. J Sports Sci. 2005;23:583-92.

8. Pasquarelli BN, Souza VAFA, Stanganelli LCR. Os Jogos com Campo Reduzido no Futebol. Rev Bras Futeb. 2010;03:02-27.

9. Abrantes CI, Nunes MI, Maçãs VM, Leite NM, Sampaio JE. Effects of the number of players and game type constraints on heart rate, rating of perceived exertion, and technical actions of small-sided soccer games. J Strength Cond Res. 2012:26:976-81.

10. Bastos MJ, Graça A, Santos P. Análise da complexidade do jogo formal versus jogo reduzido em jovens do $3^{\circ}$ ciclo do ensino básico. Rev Port Cien Desp. 2008;8:355-64.

11. Ä̧̧̈ı A. Heart rate responses during small sided-games and official match-play in soccer. Sports. 2016:4:31. 
12. Dellal A, Chamari K, Pintus A, Girard O, Cotte T, Keller D. Heart rate responses during small-sided games and short intermittent running training in elite soccer players: a comparative study. J Strength Cond Res. 2008;22(5):1449-57.

13. Duarte R, Batalha N, Folgado H, Sampaio J. Effects of exercise duration and number of players in heart rate responses and technical skills during futsal small-sided games. Open Sports Sci J. 2009;2:37-41.

14. Barbero-Alvarez JC, Soto VM, Barbero-Alvarez V, GrandaVera J. Match analysis and heart rate of futsal players during competition. J Sports Sci. 2008;26:63-73.

15. Amani-Shalamzari S, Sarikhani A, Paton C, Rajabi H, Bayati M, Nikolaidis PT, et al. Occlusion Training During Specific Futsal Training Improves Aspects of Physiological and Physical Performance. J Sports Sci Med. 2020;19 (2):374-82.

16. Carminatti LJ, Arins FB, Silva JF, Santos PC, Silva CEM, Guglielmo LGA. I ntensidade de esforço em jogos oficiais e simulados de futsal feminino. R Bras Ci Mov. 2015;23 (3):97-104.

17. Martin-Silva L, Coelho D, Condessa LA, Mortiner LAC, Araujo-Ferreira AP. Intensidade de Jogos Oficiais de Futsal Feminino. R Min Educ Fís. 2005;2:519-27.

18. Yiannaki C, Barron DJ, Collins D, Carling C. Match performance in a reference futsal team during an international tournament - implications for talent development in soccer. Biol Sport. 2020;37:147-56.

19. Silva AEL, Oliveira FRD. Estimativa dos limiares ventilatórios através da velocidade máxima em teste incremental. Motriz: J Phys Educ. 2004;10:37-44.

20. Howley ET, Bassett DR Jr, Welch HG. Criteria for maximal oxygen uptake: review and commentary. Med Sci Sports Exerc. 1995;27(9):1292-301.

21. Taylor H, Henschel A, Buskirk E. Maximal xxygen as an objective measure of cardiorespiratory performance. J Appl Physiol. 1955;8:73-80.

22. Beaver WL, Wasserman K,Whipp BJ. A new method for detecting anaerobic threshold by gas exchange. J Appl Physiol. 1986;60:2020-7.

23. Mutti D. Futsal: da iniciação ao alto nível. 2.ed. São Paulo: Phorte, 2003.
24. Cohen J. Statistical power analysis for the behavioral sciences. Lawrence Earlbaum Associates, 1988.

25. Oliveira RAA, Spineli-Silva HVR, Oliveira FR. Acclimated young and adult athletes present a psychophysiological response and exercise tolerance that is similar under cool environmental conditions and under impeded dehydration during long distance running. J.Phys Educ Sport. 2017; 17:371-7.

26. Amani-Shalamzari S, Khoshghadam E, Donyaei A, Parnow A, Bayati M, Clemente FM. Generic vs. small-sided game training in futsal: Effects on aerobic capacity, anaerobic power and agility. Physiol Behav. 2019;204:347-54.

27. Beato M, Coratella G, Schena F, Hulton AT. Evaluation of the external \& internal workload in female futsal players. Biol Sport. 2017;34:227-31.

28. Katis A, Kellis E. Effects of Small Sided Games on Physical Conditioning and Performance in Young Soccer Players. J Sport. Sci Med. 2009;8:374-80.

29. Jones S, Drust B. Physiological and technical demands of 4 v 4 and 8 v 8 games in elite youth soccer players. Kinesiology. 2007;39:150-6.

\section{Corresponding author}

Gustavo Gomes de Araujo. Universidade Federal de Alagoas, Instituto de Educação Física e Esporte, Laboratório de Ciências Aplicadas ao Esporte, Maceió, AL, Brazil.

E-mail: gusta_ef@yahoo.com.br.

Manuscript received on October 1, 2020

Manuscript accepted on May 17, 2021

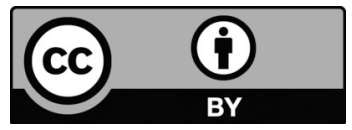

Motriz. The Journal of Physical Education. UNESP. Rio Claro, SP, Brazil - eISSN: 1980-6574 - under a license Creative Commons - Version 4.0 